\title{
Enhanced RANK ligand expression and responsivity of bone marrow cells in Paget's disease of bone
}

\author{
Cheikh Menaa, ${ }^{1}$ Sakamuri V. Reddy, ${ }^{1}$ Noriyoshi Kurihara, ${ }^{1}$ \\ Hidefumi Maeda, ${ }^{1}$ Dirk Anderson, ${ }^{2}$ Tim Cundy ${ }^{3}$ Jillian Cornish, ${ }^{3}$ \\ Frederick R. Singer, ${ }^{4}$ Jan M. Bruder, ${ }^{5}$ and G. David Roodman ${ }^{1,6}$ \\ ${ }^{1}$ Department of Medicine/Hematology, University of Texas Health Science Center at San Antonio, San Antonio, Texas, USA \\ ${ }^{2}$ Immunex Corp., Seattle, Washington, USA \\ ${ }^{3}$ University of Auckland, Auckland, New Zealand \\ ${ }^{4}$ John Wayne Cancer Center, Santa Monica, California, USA \\ ${ }^{5}$ Department of Medicine/Endocrinology, University of Texas Health Science Center at San Antonio, San Antonio, Texas, USA \\ ${ }^{6}$ Audie Murphy Veterans Administration Hospital, San Antonio, Texas, USA \\ Address correspondence to: G. David Roodman, Research (151), Audie Murphy Veterans Administration Hospital, \\ 7400 Merton Minter Boulevard, San Antonio, Texas 78284, USA. Phone: (210) 617-5319; Fax: (210) 567-4705; \\ E-mail: roodman@uthscsa.edu. \\ Received for publication December 13, 1999, and accepted in revised form May 3, 2000.
}

\begin{abstract}
Paget's disease is characterized by highly localized areas of increased osteoclast (OCL) activity. This suggests that the microenvironment in pagetic lesions is highly osteoclastogenic, or that OCL precursors in these lesions are hyperresponsive to osteoclastogenic factors (or both). To examine these possibilities, we compared RANK ligand (RANKL) mRNA expression in a marrow stromal cell line developed from a pagetic lesion (PSV10) with that in a normal stromal cell line (Saka), and expression in marrow samples from affected bones of Paget's patients with that in normal marrow. RANKL mRNA was increased in PSV10 cells and pagetic marrow compared with Saka cells and normal marrow, and was also increased in marrow from affected bones compared with uninvolved bones from Paget's patients. Furthermore, pagetic marrow cells formed OCLs at much lower RANKL concentrations than did normal marrow. Anti-IL-6 decreased the RANKL responsivity of pagetic marrow to normal levels, whereas addition of IL6 to normal marrow enhanced RANKL responsivity. Thus, RANKL expression and responsivity is increased in pagetic lesions, in part mediated by IL-6. These data suggest that the combination of enhanced expression of RANKL in affected bones and increased RANKL sensitivity of pagetic OCL precursors may contribute to the elevated numbers of OCLs in Paget's disease.
\end{abstract}

J. Clin. Invest. 105:1833-1838 (2000).

\section{Introduction}

Paget's disease is a highly localized process in which large numbers of abnormal osteoclasts (OCLs) induce increased bone resorption $(1,2)$. The primary cellular abnormality in Paget's disease resides in the OCLs. The OCLs are increased in number and size, have increased nuclei per multinucleated cell, contain paramyxoviral-like nuclear inclusions (3), and are hyperresponsive to 1,25-dihydroxyvitamin D3, or $1,25-(\mathrm{OH})_{2} \mathrm{D}_{3}$ (4). They also express high levels of osteotropic factors that can regulate OCL activity, including IL-6 (5), IL-6 receptor, and NF- $\mathrm{KB}(6)$. In addition, A.P. Mee (7) has reported that the BCL2 gene is overexpressed in OCLs from patients with Paget's disease, suggesting that the OCL life span may be prolonged in pagetic lesions. However, the basis for the increased OCL formation and the highly localized nature of Paget's disease is still unknown. Recently, RANK ligand (RANKL), a newly described member of the TNF family, has been identified as a critical osteoclastogenic factor (8-10). RANKL is expressed on marrow stromal cells and osteoblasts, and appears to mediate the effects of most osteoclastogenic factors.
In vivo studies have shown that mice lacking RANKL developed severe osteopetrosis (11). Factors such as 1,25- $(\mathrm{OH})_{2} \mathrm{D}_{3}$, IL-1, IL-11, and prostaglandin $\mathrm{E}_{2}$ appear to induce OCL formation indirectly by upregulating RANKL expression on marrow stromal cells (12). These data suggest that RANKL may be the common mediator for the effects of most osteotropic factors on OCL formation. Therefore, we have examined the relative levels of RANKL expression by marrow stromal cells from normal bones and affected bones from patients with Paget's disease, and the RANKL responsivity of OCL precursors from normal bones and affected bones from Paget's patients.

\section{Methods}

These studies were approved by the Institutional Review Board at the University of Texas Health Science Center at San Antonio and the Auckland Ethics Committee.

OCL culture. Nonadherent human bone marrow cells were collected from eight normal volunteers. Samples were also taken from involved bones of six patients with Paget's disease, and both involved and uninvolved bone from two other Paget's patients. Cells were pre- 
pared by density gradient centrifugation followed by adherence to plastic as described previously (13). All pagetic patients had elevated serum alkaline phosphatase levels and had not received bisphosphonate therapy for at least 6 months before marrow aspiration. Marrow cells $\left(10^{6}\right.$ cells $\left./ \mathrm{mL}\right)$ were cultured in $\alpha$-MEM supplemented with $20 \%$ horse serum (HyClone Laboratories, Logan, Utah, USA) in the presence or absence of recombinant human RANKL $(0-100 \mathrm{ng} / \mathrm{mL}), 25$ $\mathrm{ng} / \mathrm{mL}$ macrophage colony-stimulating factor (MCSF) (R\&D Systems Inc., Minneapolis, Minnesota, USA), and $10^{-7} \mathrm{M}$ dexamethasone (Sigma Chemical Co., St. Louis, Missouri, USA). Half of the media was replaced every 2 days. After 3 weeks of culture, the cells were fixed and then stained for cross-reactivity with the $23 c 6$ $\mathrm{mAb}$ that identifies multinucleated cells that fulfill the functional characteristics of OCLs (14). In selected experiments, RANK Fc (0-100 ng/mL) (Immunex Corp., Seattle, Washington, USA) was added to the cultures to block the effects of RANKL $(100 \mathrm{ng} / \mathrm{mL})$ on OCL formation $(15,16)$.

Stromal cell cultures. A marrow stromal cell line, PSV10, derived from an involved bone from a patient with Paget's disease (17), and a normal marrow stromal cell line, Saka (18), were cultured in $\alpha$-MEM supplemented with $10 \%$ FCS. Both of these cell lines support OCL formation. After reaching confluence, the cells were treated with $1,25-(\mathrm{OH})_{2} \mathrm{D}_{3}\left(10^{-9} \mathrm{M}\right)$ or vehicle. RNA was extracted using RNAzol (Tel-Test Inc., Friendswood, Texas, USA) following the manufacturer's instructions, and were then subjected to RT-PCR analysis for RANKL mRNA expression as described below.

Activity of c-Jun kinase. Nonadherent mononuclear bone marrow cells from two Paget's patients and three normal donors, prepared as described above, were cultured in $\alpha$-MEM and $20 \%$ horse serum in the presence of varying concentrations of RANKL $(25-100 \mathrm{ng} / \mathrm{mL})$. After 30 minutes of incubation with RANKL, the cells were harvested in ice-cold PBS and centrifuged at 700 $g$ for 5 minutes. The cells were resuspended in cell lysis buffer composed of $20 \mathrm{mM}$ Tris (pH 7.4), $150 \mathrm{mM}$ $\mathrm{NaCl}, 1 \mathrm{mM}$ EDTA, $1 \mathrm{mM}$ EGTA, $2.5 \mathrm{mM}$ sodium pyrophosphate, $1 \mathrm{mM} \beta$-glycerolphosphate, and $1 \mathrm{mM}$ sodium vanadate, in the presence of $1 \mu \mathrm{g} / \mathrm{mL}$ leupeptin, $1 \mathrm{mM}$ PMSF, and $1 \%$ Triton X-100, followed by a brief sonication. Cell lysates were cleared by centrifugation for 15 minutes at $12,000 \mathrm{~g}$. Activity of c-Jun $\mathrm{NH}_{2}$-terminal kinase was measured using a solid-phase glutathione-S-transferase-c-Jun (GST-c-Jun) (1-89 amino acids) fusion protein as described (19). Briefly, c-Jun kinase was immunoprecipitated with its substrate conjugated to glutathione-Sepharose ${ }^{\circledR}$ beads at $4^{\circ} \mathrm{C}$. After overnight incubation, the precipitates were washed twice with cell lysis buffer and then with kinase buffer composed of $25 \mathrm{mM}$ Tris ( $\mathrm{pH} 7.5$ ), $5 \mathrm{mM} \beta$-glycerolphosphate, $1 \mathrm{mM}$ sodium vanadate, $2 \mathrm{mM}$ DTT, and $10 \mathrm{mM} \mathrm{MgCl}_{2}$. After the last wash, pellets were resuspended in $50 \mu \mathrm{L}$ of kinase buffer. The reaction was carried out at $30^{\circ} \mathrm{C}$ for 30 minutes in the presence of
$100 \mu \mathrm{M}$ ATP. The reaction was stopped by adding 25 $\mu \mathrm{L}$ of $3 \times$ SDS loading buffer composed of $50 \mathrm{mM}$ Tris (pH 6.8), 100 mM DTT, 2\% SDS, 0.1\% bromophenol blue, and $10 \%$ glycerol. Proteins were separated on $12 \%$ SDS-PAGE gels and transferred to nitrocellulose filters. Phosphorylated c-Jun kinase was detected with a specific anti-phospho-c-Jun kinase $\mathrm{Ab}$ following the manufacturer's instructions (New England Biolabs Inc., Beverly, Massachusetts, USA). An indirect method was also used to measure c-Jun kinase, using anti-phosphoc-Jun kinase as described (20).

RANKL mRNA expression. We evaluated the relative levels of RANKL mRNA expression using semiquantitative RT-PCR. Briefly, RNA from the marrow stromal cell lines and total marrow samples from Paget's patients and normal individuals was reverse transcribed using Moloney leukemia virus reverse transcriptase for 15 minutes at $42^{\circ} \mathrm{C}$, followed by heating for 5 minutes at $95^{\circ} \mathrm{C}$. The reverse transcription reaction was carried out in $20 \mu \mathrm{L}$, and half of the reaction mixture was used for detecting $\beta$-actin mRNA expression. The remaining PCR reaction mixture was used for measuring RANKL expression. The gene-specific primers for RANKL mRNA (a generous gift from Babatunde Oyajobi, University of Texas Health Science Center, San Antonio, Texas, USA) (GenBank accessions AF013171, partial, and AF019047, fulllength) were 5'-ACT GGA TCC GGA TCA GGA TG-3' (sense) and 5' - AGC TGC GAA GGG GCA CAT GA-3' (antisense). PCR was performed by denaturing at $94^{\circ} \mathrm{C}$ for 1 minute followed by incubation at $60^{\circ} \mathrm{C}$ for 1 minute, for 30 cycles. These conditions were during the linear phase of the PCR reaction. The reactions were terminated by incubating at $60^{\circ} \mathrm{C}$ for 7 minutes. PCR products were separated in $1.2 \%$ agarose gel, and the relative amounts were quantitated by densitometry and corrected for $\beta$-actin mRNA levels. The primers for $\beta$-actin were $5^{\prime}$ - GGC CGT ACC ACT GGC ATC GTG ATG-3' (sense) and 5'-CAT CTC TTG CTC GAA GTC CAG GGC-3' (antisense). The PCR results were reproducible in three independent experiments.

Western blot analysis. Five million stromal cells or marrow cells were incubated in lysis buffer for 10 minutes on ice, and the total cell lysates were cleared by centrifugation at $12,000 \mathrm{~g}$ for 15 minutes. After measurement of total protein by the Bradford reaction (using a kit from Bio-Rad Laboratories Inc., Hercules, California, USA), $30 \mu \mathrm{g}$ of each lysate was separated by SDS-PAGE and then transferred to nitrocellulose filters. Nonspecific binding sites were saturated by incubating the membranes in blocking buffer $(5 \%$ nonfat milk in $10 \mathrm{mM}$ Tris at $\mathrm{pH} 8.0,150 \mathrm{mM} \mathrm{NaCl}$, and $0.1 \%$ Tween-20) for 1 hour at room temperature. Membranes were incubated with rabbit polyclonal antiRANK (1:1,500; Immunex Corp.) or a monoclonal anti-RANKL Ab (1 ng/mL) (R\&D Systems Inc.). After washing, the secondary Ab conjugated to horseradish peroxidase was added to a blocking solution and incubated for 1 hour at room temperature. Specific bands 


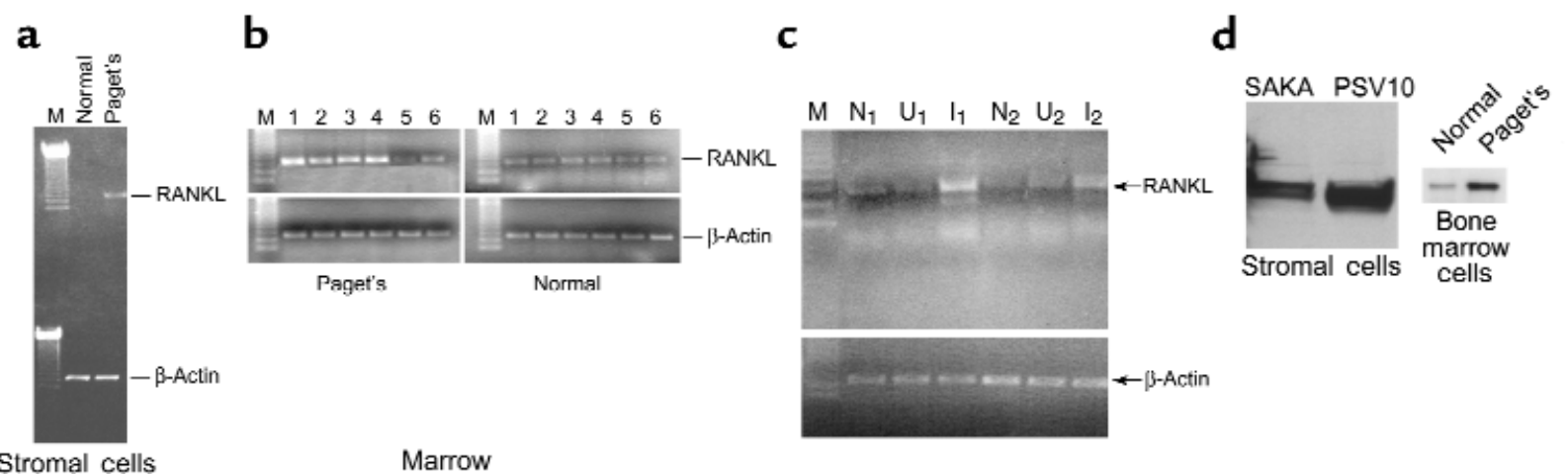

\section{Figure 1}

Expression of RANKL mRNA in bone marrow cells and stromal cells from patients with Paget's disease and normal individuals. Total RNA was extracted from normal (Saka) and Paget's (PSV10) stromal cells or from marrow samples from normal donors and involved bones from patients with Paget's disease. In addition, bone marrow aspirates were obtained from two normal individuals $(N)$ and from uninvolved $(U)$ and involved (I) bones from two patients with Paget's disease. RANKL mRNA expression was determined by RT-PCR as described in Methods. RANKL mRNA expression was elevated in six of eight patients with Paget's disease compared with eight normal donors (a, c), in the PSV10 cell line compared with Saka cells $(\mathbf{b})$, and in the involved bones of both patients $\left(I_{1}\right.$ and $\left.I_{2}\right)$ compared with uninvolved bones $\left(U_{1}\right.$ and $\left.U_{2}\right)$ from these same patients (c). The levels of mRNA expression in uninvolved bones from patients with Paget's disease were similar to those from normal individuals tested at the same time $\left(\mathrm{N}_{1}\right.$ and $\left.\mathrm{N}_{2}\right)$. Western blot analysis of marrow samples from a Paget's patient or a normal donor, and a marrow stromal cell line derived from a Paget's patient (PSV10 cells) or a normal donor (Saka cells) showed that RANKL expression was increased three- to five-fold in samples from Paget's disease patients compared with normal cells (d).

were visualized by chemiluminescence following the manufacturer's instructions (Amersham Life Sciences Inc., Arlington Heights, Illinois, USA).

Statistical analysis. Results are reported as the mean \pm SEM for four determinations, and were compared using the Student's two-tailed $t$-test. Results were considered to be significantly different at $P<0.05$.

\section{Results}

Expression of RANKL mRNA in stromal cell lines and marrow samples from Paget's patients and normal individuals. As shown in Figure 1b, RANKL mRNA expression was increased three- to fivefold in PSV10 cells compared with Saka cells. This high level of RANKL expression was also observed in bone marrow samples from pagetic lesions. RANKL expression was increased fourto fivefold in marrow from affected bones of patients with Paget's disease compared with normal marrow samples (Figure 1a). This high expression was found in six of eight Paget's patients used in this study (Fig- ure 1, a and c). Because markedly increased OCL activity in Paget's disease is observed only in affected bones, we examined the expression level of RANKL in marrow samples from affected and unaffected bones from two Paget's patients. As shown in Figure 1c, RANKL mRNA expression was increased five- to sevenfold in bone marrow aspirated from the affected bones compared with the unaffected bones in both patients. The levels of RANKL mRNA expression in uninvolved bones were similar to those in the two normal samples, which were tested simultaneously. Furthermore, to confirm that RANKL protein was also increased in Paget's patients and stromal cells, we measured RANKL expression by Western blot. In this single experiment, Western blot analysis of marrow samples from a Paget's patient and a normal donor showed a threefold increase in RANKL expression (Figure 1d). Similarly, Western blot analysis of RANKL expression in PSV10 and Saka cells showed fivefold higher RANKL expression in PSV10 cells.
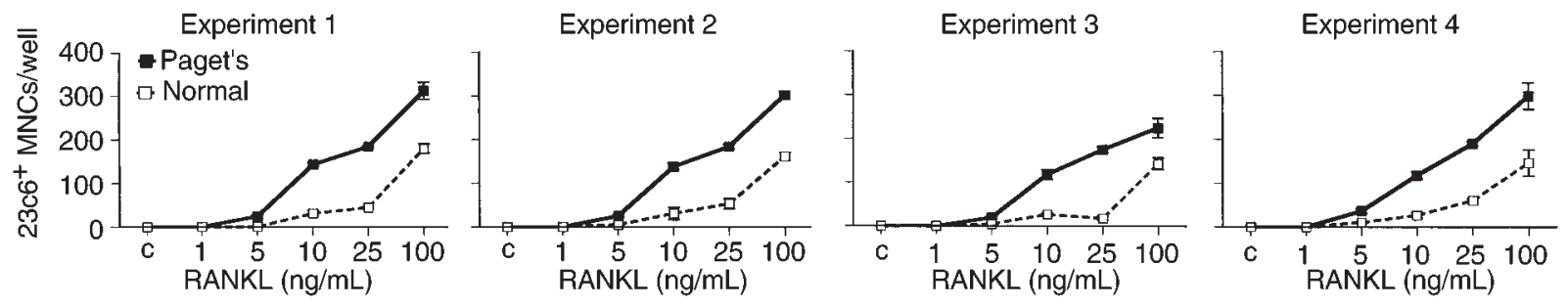

\section{Figure 2}

RANKL responsivity of marrow cells from Paget's patients and normal individuals. Marrow cells were processed as described in Methods, and were treated with varying concentrations $(0-100 \mathrm{ng} / \mathrm{mL})$ of RANKL, MCSF $(25 \mathrm{ng} / \mathrm{mL})$, and 10-7 M dexamethasone. At the end of the culture period, multinucleated cells (MNCs), which cross-reacted with the $23 \mathrm{c} 6 \mathrm{mAb}$, were scored. In the four experiments shown here, Paget's samples formed significantly more OCL-like cells at much lower concentrations of RANKL than did normal samples. 


\section{Figure 3}

Effects of RANK Fc on RANKL-induced OCL formation in marrow cultures from Paget's patients and normal individuals. Bone marrow cells were cultured with RANKL (100 ng/mL) and varying concentrations of RANK FC (0-100 ng/mL) as described in Methods. Relative inhibition of OCL formation was lower in marrow cultures from Paget's patients (solid bars) than in normal individuals (open bars) when $10-50 \mathrm{ng} / \mathrm{mL}$ of RANK Fc was added to the cultures $(P<0.05)$. Results are presented as mean \pm SEM for two independent experiments, done in quadruplicate.

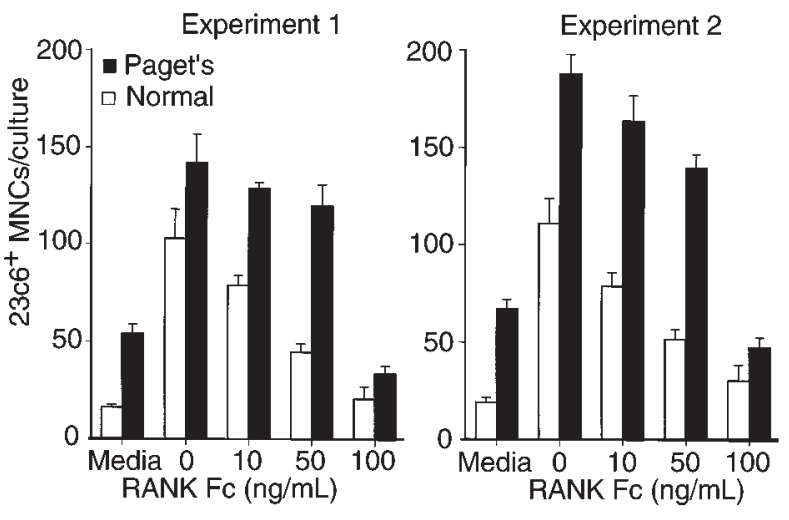

from Paget's patients were larger and contained more nuclei per multinucleated cell than those from normal marrow (Figure 4).

Activity of c-Jun kinase in Paget's and normal marrow samples. To confirm that there were differential effects of RANKL on OCL formation in Paget's marrow cultures, we measured c-Jun $\mathrm{NH}_{2}$-terminal kinase activity in an equal number of marrow cells from Paget's patients and normal individuals. c-Jun $\mathrm{NH}_{2}$-terminal kinase is an important component of the RANK/RANKL signaling pathway (19). As shown in Figure 5, RANKL $(25 \mathrm{ng} / \mathrm{mL})$ induced c-Jun kinase activity in pagetic bone marrow samples. In contrast, $100 \mathrm{ng} / \mathrm{mL}$ of RANKL was required to induce c-Jun kinase activity in normal marrow samples.

Effects of IL-6 on RANKL responsivity of OCL precursors. Because IL- 6 is expressed at higher levels in marrow from affected bones of patients with Paget's disease than in normal marrow (5), we sought to determine whether IL6 was involved in the enhanced responsivity of marrow cells from Paget's patients to RANKL. Therefore, we cultured bone marrow from Paget's patients with $10 \mathrm{ng} / \mathrm{mL}$ of RANKL, $25 \mathrm{ng} / \mathrm{mL} \mathrm{MCSF}$, and $10^{-7} \mathrm{M}$ dexamethasone,

\section{Figure 4}

OCL-like cells formed in marrow cultures from patients with Paget's disease and normal individuals. Bone marrow mononuclear cells were prepared as described in Methods and then treated with 10 $\mathrm{ng} / \mathrm{mL}$ or $25 \mathrm{ng} / \mathrm{mL}$ of RANKL plus $25 \mathrm{ng} / \mathrm{mL}$ MCSF and $10^{-7} \mathrm{M}$ dexamethasone. $\mathrm{OCL}-$ like cells that were markedly increased in number and size formed in marrow cultures from Paget's patients at low concentrations of RANKL $(10 \mathrm{ng} / \mathrm{mL})$ compared with normal marrow (143 \pm 4 for Paget's marrow vs. 31 \pm 6 for normal marrow). At the higher concentration of RANKL $(25 \mathrm{ng} / \mathrm{mL})$, the numbers of OCL-like cells formed in pagetic marrow cultures were also higher than in normal cultures ( $184 \pm 2$ for Paget's marrow vs. $44 \pm 2$ for normal marrow). Similar results were seen in five independent experiments. Arrows point to OCL-like cells.

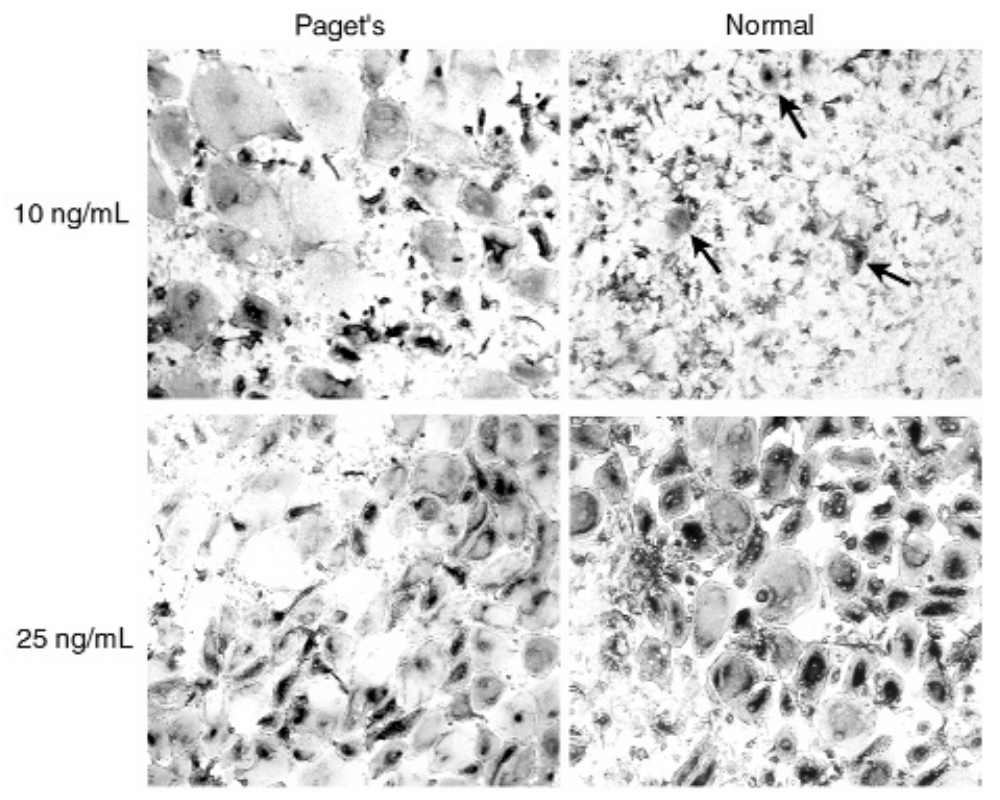




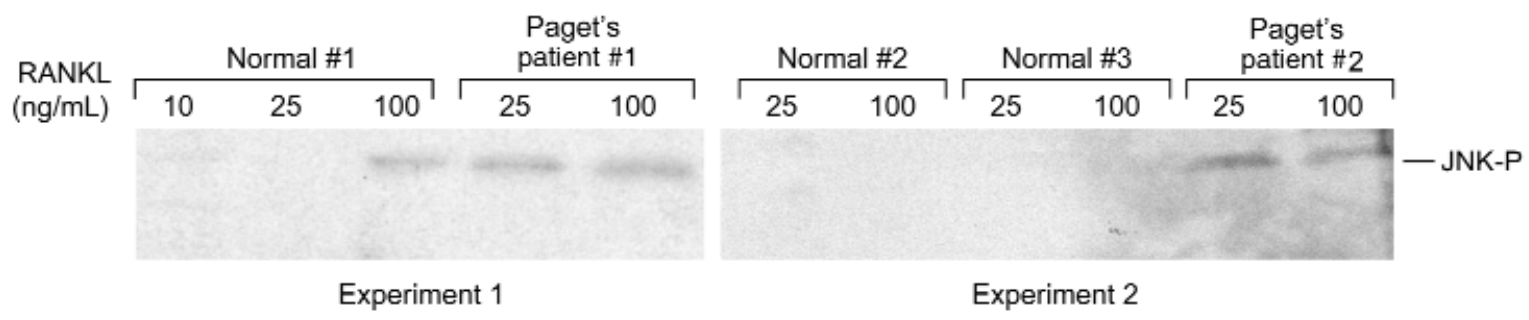

Figure 5

Activity of c-Jun kinase in Paget's and normal bone marrow cultures in response to RANKL. Bone marrow cells from two Paget's patients and three normal individuals were prepared as described in Methods and treated with RANKL (25-100 ng/mL). Phosphorylated c-Jun kinase (JNK-P) was measured as described in Methods, and the levels of c-Jun kinase activity in Paget's and normal individuals were compared. Lower concentrations of RANKL (25 ng/mL vs. $100 \mathrm{ng} / \mathrm{mL}$ ) showed c-Jun kinase activity in marrow samples from Paget's patients compared with normal individuals. The results represent two independent experiments.

and varying concentrations of a neutralizing Ab to IL- 6 (anti-IL-6) or nonspecific IgG. As shown in Figure 6a, addition of anti-IL-6 decreased the responsivity of Paget's marrow cells to RANKL. This effect was dose dependent and not related to any toxicity of anti-IL-6. Addition of nonspecific $\operatorname{Ig} G$ to these marrow cultures had no effect on RANKL responsivity of normal or Paget's cells (data not shown). To confirm that IL-6 could affect the RANKL responsivity of OCL precursors to RANKL, we added $200 \mathrm{pg} / \mathrm{mL}$ of IL- 6 to normal marrow cultures treated with RANKL (10 ng/mL), MCSF $(25 \mathrm{ng} / \mathrm{mL})$, and dexamethasone $\left(10^{-7} \mathrm{M}\right)$. As shown in Figure 6b, IL-6 enhanced the responsivity of normal marrow cells to RANKL. Concentrations of RANKL as low as $10 \mathrm{ng} / \mathrm{mL}$ could induce OCL formation in normal marrow cultures to levels similar to those induced by RANKL $(10 \mathrm{ng} / \mathrm{mL})$ in pagetic bone marrow cells. IL- 6 by itself did not induce OCL formation under these culture conditions.

Expression of RANK in marrow samples from Paget's patients and normal individuals. To further investigate the mechanism responsible for the enhanced RANKL sen- sitivity of OCL precursors from Paget's patients, we determined if RANK, the receptor for RANKL, was upregulated in bone marrow cells from Paget's patients. Western blot analysis of lysates of these cells confirmed that there was no difference in the levels of RANK expression between normal and pagetic marrow samples (data not shown).

\section{Discussion}

In this study, we found that RANKL mRNA is relatively overexpressed in a pagetic stromal cell line and in marrow samples from involved bones from Paget's patients compared with a normal stromal cell line and normal marrow cells. Furthermore, RANKL mRNA expression was also increased in bone marrow aspirated from involved bones, compared with the uninvolved bones from the same patients. Thus, RANKL appears to be highly expressed only in the involved bones of Paget's patients. The reason for the increased expression levels of RANKL is not known, but it does not appear to be related to high levels of IL- 6 expression, because high

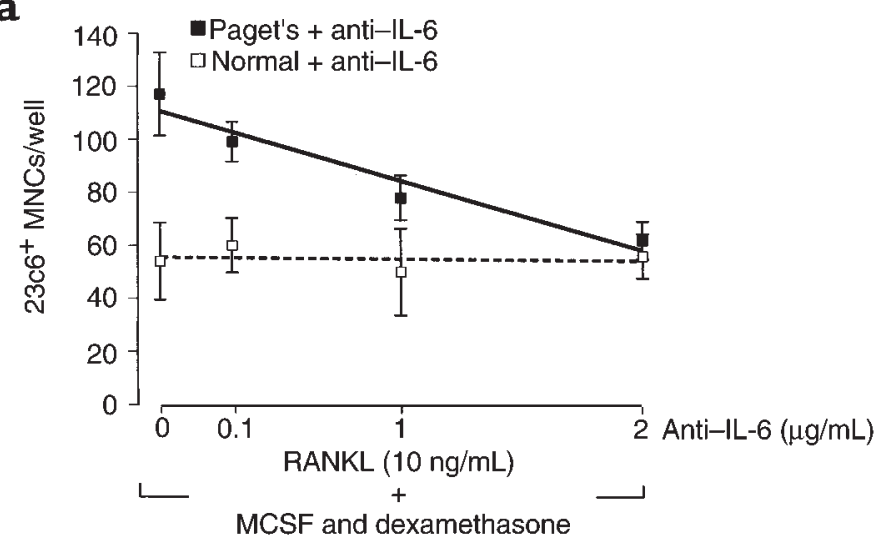

b

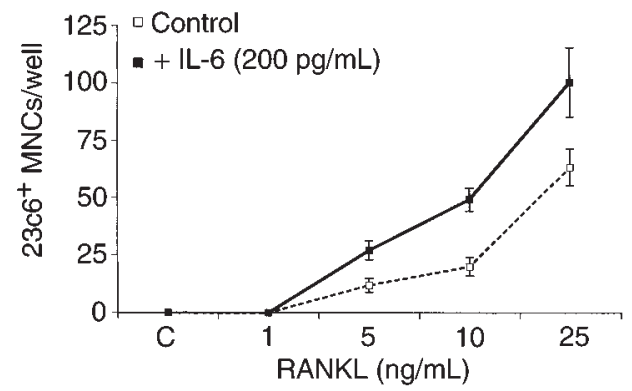

\section{Figure 6}

Effects of anti-IL-6 and IL-6 on the responsivity of Paget's and normal marrow cultures to RANKL. (a) Marrow mononuclear cells from Paget's patients or normal donors were prepared as described in Methods and then cultured with $10 \mathrm{ng} / \mathrm{mL}$ of RANKL plus $25 \mathrm{ng} / \mathrm{mL} \mathrm{MCSF}$ and $10^{-7} \mathrm{M}$ dexamethasone in the presence of varying concentrations of a neutralizing Ab to IL-6. Increasing concentrations of anti-IL-6 decreased the RANKL responsivity of marrow cells from Paget's patients to normal levels. (b) Addition of IL- 6 ( 200 pg/mL) to normal marrow cultures enhanced RANKL responsivity compared with cultures treated with media alone. Results are shown as mean \pm SEM for a typical experiment. Similar results were seen in three independent experiments. 
concentrations of IL- 6 do not increase RANKL expression in human stromal cells or osteoblasts (ref. 21 and unpublished data from Menaa et al.). These results are in contrast to those of O'Brien et al. (22), who have shown that IL-6 in combination with soluble IL-6 receptor increased RANKL expression in a murine marrow stromal cell line, suggesting that human and murine stromal cells respond differently to IL-6.

In addition to increased expression of RANKL in pagetic lesions, OCL precursors from Paget's patients appear to be hyperresponsive to RANKL. Very low concentrations of RANKL induced OCL formation in Paget's marrow cultures, whereas much higher concentrations of RANKL were required for OCL formation in normal marrow cultures. Furthermore, anti-IL- 6 decreased the RANKL responsivity of OCL precursors from Paget's patients to normal levels, and IL- 6 increased the RANKL responsivity of normal marrow cells. We previously demonstrated that elevated levels of IL- 6 are present in the bone marrow of patients with Paget's disease compared with marrow of normal individuals (5). Similarly, Hoyland and coworkers (6), using in situ hybridization, showed that pagetic OCLs express high levels of IL-6 mRNA, as well as IL- 6 receptor mRNA. Similarly, recent studies by Wani et al. (23) showed that other factors, such as prostaglandin $E_{2}$, can also increase the sensitivity of OCL precursors from murine spleen cells to RANKL.

The increased RANKL sensitivity of OCL precursors from Paget's patients could also result from increased expression of the RANKL receptor, RANK, on OCL precursors from Paget's patients. Anderson et al. (15) have shown that overexpression of RANK can induce $\mathrm{NF}-\kappa \mathrm{B}$ signaling even in the absence of RANKL. However, our results show that RANK expression levels are similar in marrow samples from normal individuals and Paget's patients.

These data suggest that the combined increased local expression of RANKL and hyperresponsivity of OCL precursors to RANKL, due in part to IL-6, may contribute to the increased numbers of OCLs in pagetic lesions and the localized nature of the disease. The mechanism responsible for the increased expression of RANKL in Paget's disease remains to be determined, but may reflect the effects of cytokines other than IL- 6 upregulating RANKL expression in marrow stromal cells.

\section{Acknowledgments}

The authors thank Bibi Cates for preparation of the manuscript. This work was supported by research funds from the Veterans Administration and by National Institutes of Health grants AR-44603, AR-41336, DE12603 , and AG-13625.
1. Hosking, D.J. 1981. Paget's disease of bone. Br. Med. J. (Clin. Res. Ed.) 283:686-688.

2. Yates, A.J. 1988. Paget's disease of bone. Baillieres Clin. Endocrinol. Metab. 2:267-285.

3. Rebel, A., Malkani, K., Basle, M., and Bregeon, C.H. 1976. Osteoclast ultrastructure in Paget's disease. Calcif. Tissue Res. 20:187-199.

4. Kukita, A., Chenu, C., McManus, L.M., Mundy, G.R., and Roodman, G.D. 1990. Atypical multinucleated cells form in long-term marrow cultures from patients with Paget's disease. J. Clin. Invest. 85:1280-1286.

5. Roodman, G.D., et al. 1992. Interleukin-6: a potential autocrine/paracrine factor in Paget's disease of bone. J. Clin. Invest. 89:46-52.

6. Hoyland, J.A., Freemont, A.J., and Sharpe, P.T. 1994. Interleukin-6, IL-6 receptor, and IL-6 nuclear factor gene expression in Paget's disease. J. Bone Miner. Res. 9:75-80.

7. Mee, A.P. 1999. Paramyxoviruses and Paget's disease: the affirmative view. Bone. 24(Suppl. 5):19S-21S.

8. Lacey, D.L., et al. 1998. Osteoprotegerin ligand is a cytokine that regulates osteoclast differentiation and activation. Cell. 93:165-176.

9. Yasuda, H., et al. 1998. Osteoclast differentiation factor is a ligand for osteoprotegerin/osteoclastogenesis-inhibitory factor and is identical to TRANCE/RANKL. Proc. Natl. Acad. Sci. USA. 95:3597-3602.

10. Hofbauer, L.C., and Heufelder, A.E. 1998. Osteoprotegerin and its cognate ligand: a new paradigm of osteoclastogenesis. Euro. J. Endocrinol. 139:152-154.

11. Kong, Y.Y., et al. 1999. OPGL is a key regulator of osteoclastogenesis, lymphocyte development and lymph-node organogenesis. Nature. 397:315-323.

12. Yasuda, H., et al. 1998. Identity of osteoclastogenesis inhibitory factor (OCIF) and osteoprotegerin (OPG): a mechanism by which OPG/OCIF inhibits osteoclastogenesis in vitro. Endocrinology. 139:1329-1337.

13. Kurihara, N., Bertolini, D., Suda, T., Akiyama, Y., and Roodman, G.D. 1990. IL-6 stimulates osteoclast-like multinucleated cell formation in long-term human marrow cultures by inducing IL-1 release. J. Immunol. 144:4226-4230.

14. Kurihara, N., Chenu, C., Miller, M., Civin, C.I., and Roodman, G.D. 1990. Identification of committed mononuclear precursors for osteoclast-like cells formed in long-term marrow cultures. Endocrinology. 126:2733-2741.

15. Anderson, D.M., et al. 1997. A homologue of the TNF receptor and its ligand enhance T-cell growth and dendritic-cell function. Nature. 390:175-179.

16. Hsu, H., et al. 1999. Tumor necrosis factor receptor family member RANK mediates osteoclast differentiation and activation induced by osteoprotegerin ligand. Proc. Natl. Acad. Sci. USA. 96:3540-3545.

17. Devlin, R.D., Reddy, S.V., Savano, R., Ciliberto, G., and Roodman, G.D. 1998. IL-6 mediates the effects of IL-1 or TNF, but not PTHrP or 1,25$(\mathrm{OH})_{2} \mathrm{D}_{3}$, on osteoclast-like cell formation in normal human bone marrow cultures. J. Bone Miner. Res. 13:393-399.

18. Takahashi, S., et al. 1995. Development and characterization of a human marrow stromal cell line that enhances osteoclast-like cell formation. Endocrinology. 136:1441-1449.

19. Wong, B.R., et al. 1997. TRANCE is a novel ligand of the tumor necrosis factor receptor family that activates c-Jun $\mathrm{N}$-terminal kinase in T cells. $J$. Biol. Chem. 272:25190-25194.

20. Osao, I., Tani, E., Ikemoto, H., Kitagawa, H., and Fujikawa, H. 1999. Activation of stress-activated and $\mathrm{p} 38$ kinase in calphostin $\mathrm{C}$-induced apoptosis requires caspase-3-like proteases but is indispensable for cell death. J. Biol. Chem. 274:5310-5317.

21. Hofbauer, L.C., et al. 1999. Interleukin-1-beta and tumor necrosis factor-alpha, but not interleukin-6, stimulate osteoprotegerin ligand gene expression in human osteoblastic cells. Bone. 25:255-259.

22. O’Brien, C.A., Gubrij, I., Lin, S.C., Saylors, R.L., and Manolagas, S.C. 1999. STAT3 activation in stromal/osteoblastic cells is required for induction of the receptor activator of NF-kappaB ligand and stimulation of osteoclastogenesis by gp130-utilizing cytokines or interleukin-1 but not 1,25-dihydroxyvitamin D3 or parathyroid hormone. J. Biol. Chem. 274:19301-19308.

23. Wani, M.R., Fuller, K., Kim, N.S., Choi, Y., and Chambers, T. 1999. Prostaglandin E2 cooperates with TRANCE in osteoclast induction from hemopoietic precursors: synergistic activation of differentiation, cell spreading, and fusion. Endocrinology. 140:1927-1935. 